\title{
POLÍTICA E MEIO AMBIENTE: A INFLUÊNCIA DO LOBBYNAS DECISÕES LEGISLATIVAS
}

\author{
João Eduardo Branco de Melo* \\ Adriano Fritzen** \\ Sandra Beatriz Vicenci Fernandes*** \\ Dieter Rugard Siedenberg**** \\ Sérgio Luís Allebrandt*****
}

\begin{abstract}
Resumo
O presente estudo pretende analisar a influência do lobby no poder legislativo brasileiro, mais especificamente a pressão exercida sobre os presidentes da Comissão de Meio Ambiente e Desenvolvimento Sustentável, na Câmara dos Deputados e na Comissão de Meio Ambiente, Defesa do Consumidor e Fiscalização e Controle, do Senado Federal. Em um primeiro, momento é necessário caracterizar o lobby e de que forma ele atua; posteriormente, é realizada a identificação dos presidentes de cada comissão dentro das casas legislativas e, em seguida, o levantamento de dados de financiamento de campanha de cada um deles. Observamos que nas campanhas eleitorais dos parlamentares estudados atuaram como financiadoras empresas do ramo do agronegócio, da construção civil, do sistema financeiro, entre outros. As empresas destes segmentos realizam influência direta no posicionamento e nas decisões proferidas pelas casas legislativas, pois o fator econômico se mostra um diferencial nas campanhas eleitorais brasileiras.
\end{abstract}

Palavras-chave: Meio ambiente. Campanha eleitoral. Lobby.

\footnotetext{
* Mestre pelo Programa de Pós-graduação stricto sensu em Desenvolvimento Regional da Universidade Regional do Noroeste do Estado do Rio Grande do Sul (Unijuí/RS). E-mail: joaoeduuardo1@gmail.com

** Mestre em Desenvolvimento pela Universidade Regional do Noroeste do Estado do Rio Grande do Sul (Unijuí/RS). E-mail: adrianofritzen@gmail.com

*** Doutora em Ciências do Solo pela Universidade Federal do Rio Grande do Sul. Docente do Programa de Pós-graduação stricto sensu em Desenvolvimento Regional da Universidade Regional do Noroeste do Estado do Rio Grande do Sul (Unijuí/RS). E-mail: sandravf@unijui.edu.br

**** Doutor em Geografia Econômica sobre Desenvolvimento Regional - Universitat Tuebingen/Alemanha. Docente do Programa de Pós-graduação stricto sensu em Desenvolvimento Regional da Universidade Regional do Noroeste do Estado do Rio Grande do Sul (Unijuí/RS).E-mail: dieterrs@unijui.edu.br

****** Doutor em Desenvolvimento Regional pelo PPGDR/UNISC. Docente do Programa de Pós-graduação stricto sensu em Desenvolvimento Regional da Universidade Regional do Noroeste do Estado do Rio Grande do Sul (Unijuí/RS). E-mail: allebr@unijui.edu.br
} 


\section{Introdução}

Os estudos desenvolvidos por um grupo de pesquisadores, conhecido como "Clube de Roma", nos anos 1960 do Século XX despertaram um maior interesse dos líderes mundiais na questão ambiental. Após a repercussão destes estudos foi realizada a Conferência das Nações Unidas sobre o Meio Ambiente Humano, em Estocolmo, capital da Suécia, no ano de 1972, conhecida como Conferência de Estocolmo, considerada a primeira grande reunião de chefes de Estados organizada pela Organização das Nações Unidas (ONU) para tratar das questões relacionadas à degradação do meio ambiente.

As questões relativas ao meio ambiente tiveram uma maior visibilidade após a II Guerra Mundial, também com a publicação de estudos na área, assim como as conferências que foram realizadas, mas principalmente depois dos desastres ambientais que aconteceram, por exemplo, o acidente nuclear na cidade de Chernobyl.

Outro fator importante no que se refere às questões ambientais foi a publicação do Relatório de Brundtland em 1987. Alguns anos depois, ocorreu a Conferência das Nações Unidas sobre Meio Ambiente e Desenvolvimento, na cidade do Rio de Janeiro em 1992, mais conhecida como Rio 92. Esta conferência é considerada como um dos mais importantes encontros voltados à questão ambiental já realizado na história da humanidade.

A partir da redemocratização brasileira e da promulgação da Constituição Federal, em 5 de outubro de 1988, a pauta sobre a importância do meio ambiente e de sua preservação foi elevada ao nível constitucional, ou seja, tornou-se um compromisso do Estado e de todos os brasileiros a preservação ambiental.

Após a Constituição Federal e a Rio 92, o país naturalmente começou a pautar as questões ambientais como mais um instrumento que deveria estar presente na política, o que fez com que fossem criadas as comissões que versam sobre o meio ambiente.

Portanto, o presente estudo aborda a investigação dos ramos das atividades que exercem influência, ou seja, o lobby, a partir do financiamento das campanhas eleitorais dos presidentes das comissões sobre o meio ambiente da Câmara dos Deputados e do Senado Federal no Brasil.

Este estudo, além desta introdução, divide-se nas seguintes seções: procedimentos metodológicos a serem utilizados; revisão bibliográfica sobre temas relacionados à política e ao meio ambiente; apresentação da Comissão de Meio Ambiente e Desenvolvimento Sustentável da Câmara dos Deputados (CMADS), e evidenciação dos valores recebidos para utilização em campanhas eleitorais pelos presidentes desta comissão; 
caracterização da Comissão de Meio Ambiente, Defesa do Consumidor e Fiscalização e Controle do Senado Federal, bem como a apresentação das doações recebidas nas campanhas eleitorais pelos presidentes desta comissão; e Considerações finais.

Procedimentos Metodológicos

Utilizou-se a revisão da literatura existente sobre as questões políticas voltadas ao meio ambiente, bem como consulta a dados e informações relacionadas à temática definida como foco deste estudo.

Optou-se pela análise de conteúdo de Bardin (2011),como ferramenta metodológica para a consecução dos objetivos deste estudo. A análise de conteúdo pode ser entendida como um conjunto de procedimentos e técnicas utilizadas para a análise das informações prestadas, obtidas de onde o pesquisador irá basear seu trabalho. A análise de conteúdo se desenvolveu a partir do início do século XX, podendo ser realizada de forma qualitativa, quantitativa ou ambas (VERGARA, 2008).

Dessa forma, a análise de conteúdo divide-se em três etapas que são as seguintes: pré-análise que se refere à seleção do material e dos procedimentos a serem seguidos; exploração do material que trata da implementação dos procedimentos; e o tratamento de dados, os quais são analisados e apresentados de forma a confirmar ou não as teorias utilizadas como referências (VERGARA, 2010).

Neste estudo, primeiramente, ocorreu uma pré-análise dos dados obtidos a partir de pesquisas realizadas, visto que a mesma consistiu na seleção dos mesmos. Logo em seguida, foram explorados e analisados os dados e materiais, sendo apresentados a partir nas seções 4 e 5 deste estudo.

Política e Meio Ambiente

A Constituição Federal de 1988 definiu como será realizada a composição do poder legislativo brasileiro, mais especificamente no art. 45, o qual estabelece que a Câmara de Deputados é composta de representantes do povo; no art. 46, define que o Senado Federal compõe-se de representantes dos Estados e do Distrito Federal (BRASIL, 1988).

Portanto, os políticos brasileiros que compõem o Poder Legislativo representam o povo e os Estados e exercem essa representatividade nas comissões específicas de cada casa, tais como a Comissão de Meio Ambiente e Desenvolvimento Sustentável. Porém, quando se observa de maneira mais atenta e profunda sobre esse papel, é perceptível que muitas vezes o interesse da população, como um meio ambiente limpo e adequado, não é defendido da maneira que deveria ou como o povo gostaria, e em muitas situações isso pode ser constatado no discurso, em algum posicionamento ou nas votações dos políticos que ocupam os cargos de confiança e que definem os rumos do país. 
Diante dessa situação, a pergunta que surge por parte dos cidadãos parece muito simples: por quê? Entretanto, tal resposta nem sempre se mostra límpida e transparente. Desse modo, uma das situações que podem ser ressaltadas refere-se à influência que grupos empresariais e outros stakeholders efetuam sob os políticos, com o intuito de, no futuro, exercer pressão para a aprovação ou não de leis, políticas públicas e outras formas de privilégios. Essa situação, guardadas as devidas proporções, pode ser entendida como uma forma de lobby na atuação dos políticos brasileiros.

Mostra-se necessária a definição de lobby, termo que, de acordo com o dicionário Michaelis, é a atividade de pressão por parte de um grupo organizado, a fim de exercer influência no voto de parlamentares, conforme determinados interesses.

O presente trabalho pretende analisar os políticos que são presidentes das comissões que versam sobre o meio ambiente e as doações que eles receberam de financiamento de campanha, procurando identificar os financiadores e também o lobby, ou seja, os reais interesses e interessados que estão sendo representados no Poder Legislativo brasileiro. "Apesar de todos os temores envolvidos, as doações de empresas se tornaram um importante meio de identificar e compreender o entrelaçamento de determinados setores da sociedade com os partidos políticos e nossos candidatos" (BORGES, 2016).

Em alguns países o lobby é legalizado e considerado uma atividade profissional exercida por diversas pessoas. Já no Brasil, o lobby pode configurar-se como crime, caracterizando-se em uma contravenção à lei ${ }^{1}$.

Na concepção de Diniz e Boschi (1999, p. 20), a ação dos lobbies está,

[...] em grande parte, associada à corrupção, aliciamento, tráfico de influência, enfim, a uma forma ilícita de pressão. Esta é a imagem pública dominante. Entre os políticos, não se observa esse grau de rigidez, observando-se diferentes matrizes na avaliação dos efeitos do lobbying. Tal diversidade inclui desde que os consideram que os efeitos negativos decorrem principalmente do fato de a atividade não estar regulamentada, até os que percebem tal prática como inerentemente ilegítima e prejudicial.

No Brasil, as campanhas eleitorais têm um alto custo, o que revela que um cargo público é alvo de muita disputa e os políticos, nas eleições de 2014, eram autorizados a receber doações privadas com o intuito de financiar suas campanhas eleitorais ${ }^{2}$ visto que na época esta era uma prática legítima no ordenamento jurídico brasileiro. No ano de 2015, foi criada a Lei $n^{\circ} 13.165$ que visa, entre outras coisas, à redução dos custos das campanhas ao estabelecer limite de gastos e também ao proibir o financiamento de campanha por parte de empresas ou grupos empresariais ${ }^{3}$.
1 Cabe destacar aqui o PL $\mathrm{n}^{\circ}$ 1.202/2007 de autoria do Deputado Carlos Zarattini (PT/SP) que está pronta para ir ao plenário e visa a disciplinar a atividade do lobby e a atuação dos grupos de pressão ou de interesse. Neste mesmo sentido, o senador Romero Jucá (PMDB/RR) propôs a Proposta de Emenda à Constituição no 47/2016, denominada PEC do lobby, que pretende alterar a Constituição Federal para regulamentar a atividade de representação de interesses perante o Poder Público.

2 O financiamento de campanha no ordenamento jurídico brasileiro é definido pelas seguintes leis: $n^{\circ} 9.504 / 97, n^{\text {o }} 11.300 / 2006$ e no $13.165 / 2015$.

3 Art. 20. "O candidato a cargo eletivo fará, diretamente ou por intermédio de pessoa por ele designada, a administração financeira de sua campanha usando recursos repassados pelo partido, inclusive os relativos à cota do Fundo Partidário, recursos próprios ou doações de pessoas físicas, na forma estabelecida nesta Lei” (BRASIL, 2015). 
Sobre as doações privadas a campanhas eleitorais, Sztutman e Aldrighi (2012, p. 3) alertam que

Apesar de serem um mecanismo legítimo de participação política, doações privadas podem ser motivadas pela expectativa dos doadores de influenciar as decisões dos candidatos quando eleitos, corrompendo a democracia em pelo menos dois aspectos. Primeiro, tornam os cidadãos politicamente mais desiguais, pois favorecem os candidatos que possuem mais recursos ou relações mais próximas com empresários. Em segundo lugar, os financiadores de campanha ficam na posição de "credores" dos candidatos eleitos, compelindoos a decisões políticas enviesadas.

Essa situação acaba enfraquecendo a democracia e suas instituições nos diferentes poderes, tanto no legislativo como no executivo. As doações privadas podem, em determinadas situações e assuntos, condicionar as decisões dos agentes políticos aos interesses dos financiadores de suas campanhas eleitorais, provocando um desequilíbrio de poderes na sociedade.

Ainda nesse contexto, Diniz e Boschi (1999, p. 5) ressaltam que:

As conexões entre interesses empresariais e a esfera governamental assumiriam preponderantemente a forma de vínculos pessoais, em que a participação de empresários nas instâncias decisórias se faria não na qualidade de representantes de classe, mas enquanto lideranças de prestígio ou dirigentes de empresas dotadas de forte peso econômico.

Accioly e Sánchez (2012, p. 103) define que os grupos ou indivíduos

[...] se organizam para exercer pressão a favor da flexibilização da legislação ambiental e do desmonte do aparato público administrativo para a gestão ambiental, assim como a redução de verbas públicas para a fiscalização; adotam a política do "fato consumado" para a aprovação de leis a seu favor; atacam movimentos ambientalistas, desqualificando-os pretensamente em prol da "soberania nacional" e do "interesse social relevante", gerando confusão e confundindo a opinião pública deliberadamente.

As comissões parlamentares da Câmara dos Deputados e do Senado Federal podem ser permanentes ou temporárias, com funções legislativas e fiscalizadoras, na forma definida pela Constituição Federal e nos seus respectivos regimentos internos. No cumprimento dessas duas funções básicas, de elaboração de leis e de acompanhamento das ações administrativas, no âmbito do poder executivo, as comissões promovem, também, debates e discussões com a participação da sociedade em geral, sobre todos os temas ou assuntos de seu interesse (BRASIL, 2006a). 
É também no âmbito das comissões que se apresentam e se estudam todos os dados, antecedentes, circunstâncias e conveniência de um projeto. Por meio das comissões, esses aspectos sofrem ampla discussão e há mais liberdade para expressão das opiniões e formação do consenso que, emitido sob a forma de parecer da comissão, irá orientar o plenário na apreciação da matéria (BRASIL, 2006a).

Isso significa que as comissões são muito importantes e se mostram como uma arena de debates onde há muitos interesses em jogo. E é dentro dessas arenas que podemos analisar as votações dos políticos membros e a que ou quem eles representam.

Comissão de Meio Ambiente e Desenvolvimento Sustentável

No ano de 1989, foi criada a Comissão de Defesa do Consumidor e Meio Ambiente na Câmara dos Deputados para discutir temas ligados ao meio ambiente. Já no ano seguinte, acrescentou-se a comissão o tema "Minorias", o qual foi tratado até o ano de 2004 (BRASIL, 2006a).

Já em 18 de março de 2004, por meio da Resolução no 20 de 2004, desmembrou-se da então Comissão de Defesa do Consumidor, Meio Ambiente e Minorias, para a instituição da Comissão de Meio Ambiente e Desenvolvimento Sustentável (CMADS), da Câmara dos Deputados, com a finalidade de discutir as temáticas relacionadas ao meio ambiente (BRASIL, 2006a).

Os assuntos delimitados como área de atuação a serem discutidos pela CMADS são os definidos no Regimento Interno da Câmara, que são os seguintes: a) política e sistema nacional do meio ambiente; direito ambiental; legislação de defesa ecológica; b) recursos naturais renováveis; flora, fauna e solo; edafologia e desertificação; c) desenvolvimento sustentável (BRASIL, 2006a).

A comissão é composta de 18 membros titulares, em conformidade com o disposto no Ato da Mesa no 55/2005. A composição parlamentar desses órgãos técnicos é renovada a cada ano ou sessão legislativa (BRASIL, 2006a). A CMADS, para o biênio 2015/2016 foi presidida pelo Deputado Luiz Lauro Filho do PSB/SP.

A Tabela 1 apresenta a relação de doadores da campanha eleitoral do Presidente da CMADS nas últimas eleições para deputado federal em 2014, por ramo de atividade principal exercida pelo doador. 
Tabela 1 - Doadores do Deputado Luiz Lauro Filho PSB/SP

\begin{tabular}{lcc}
\hline Atividade & Valor R\$ & \% \\
\hline Agribusiness & $250.000,00$ & 8,36 \\
Atividades de Saúde & $45.419,46$ & 1,52 \\
Comércio & $600.000,00$ & 20,07 \\
Construção civil & $1.408 .718,85$ & 47,13 \\
Veículos & $684.967,50$ & 22,92 \\
\hline Total & $2.989 .105,81$ & 100,00 \\
\hline
\end{tabular}

Fonte: Adaptada de Brasil (2014).

Conforme a Tabela 1 informa, 47,13\% dos doadores da campanha do presidente da Comissão de Meio Ambiente e Desenvolvimento Sustentável da Câmara de Deputados são advindos da construção civil, e possuem interesse nas questões que são deliberadas por tal comissão, pois isso influencia diretamente em suas atividades financeiras.

A Tabela 2 apresenta a relação de doadores da campanha eleitoral do Presidente da CMADS para o biênio 2017/2018, o deputado federal Nilto Tatto do PT/SP, nas últimas eleições para deputado federal em 2014, por ramo de atividade principal exercida pelo doador.

Tabela 2 - Doadores do Deputado Nilto Tatto PT/SP

\begin{tabular}{lcc}
\hline Atividade & Valor $\mathbf{R} \$$ & $\mathbf{\%}$ \\
\hline Construção civil & $1.581 .725,00$ & 85,74 \\
Petrolífera & $19.000,00$ & 1,03 \\
Sistema Financeiro & $50.000,00$ & 2,71 \\
Outros & $194.135,61$ & 10,52 \\
\hline Total & $1.844 .860,61$ & 100,00 \\
\hline
\end{tabular}

Fonte: Adaptada de Brasil (2014).

Conforme se observa na Tabela 2, 85,74\% dos doadores da campanha do presidente da Comissão de Meio Ambiente e Desenvolvimento Sustentável da Câmara de Deputados são advindos de empresas que têm como atividade principal a construção civil e possuem interesse nas questões que são deliberadas por tal comissão.

Portanto, constata-se que os principais doadores das campanhas eleitorais dos deputados que presidiram a Comissão de Meio Ambiente e Desenvolvimento Sustentável da Câmara de Deputados no período de 2015 a 2018 são ligados à atividade de construção civil, setor que comprovadamente está envolvido em um dos maiores esquemas de corrupção da história do Brasil, no qual estão sendo investigadas como participantes as grandes empresas do ramo, como: Odebrecht, Camargo e Correia, entre outras. 
Comissão de Meio Ambiente, Defesa do Consumidor e Fiscalização e Controle

A Comissão de Meio Ambiente, Defesa do Consumidor e Fiscalização e Controle (CMA), do Senado Federal, é responsável por discutir ações vinculadas e temáticas relativas ao meio ambiente, dentre outras atividades. A comissão é composta por 17 membros titulares e 17 membros suplentes (BRASIL, 2016b).

Compete a CMA, em conformidade com art. 102-A, inciso II, do Regimento Interno do Senado Federal, dentre outras funções:

a) proteção do meio ambiente e controle da poluição, conservação da natureza, defesa do solo e dos recursos naturais e genéticos, florestas, caça, pesca, fauna, flora e recursos hídricos;

b) política e sistema nacional de meio ambiente;

c) preservação, conservação, exploração e manejo de florestas e da biodiversidade;

d) conservação e gerenciamento do uso do solo e dos recursos hídricos, no tocante ao meio ambiente e ao desenvolvimento sustentável;

e) fiscalização dos alimentos e dos produtos e insumos agrícolas e pecuários, no tocante ao meio ambiente e ao desenvolvimento sustentável;

f) direito ambiental;

g) agências reguladoras na área de meio ambiente, inclusive a Agência Nacional de Águas - ANA;

h) outros assuntos correlatos; (BRASIL, 2016b).

Nos anos de 2015 e 2016, o presidente da CMA foi o Senador Otto Alencar do PSD/BA. Desse modo, a Tabela 3 apresenta os doadores à campanha eleitoral dele, sendo estes representados por atividades principais exercidas pelas empresas doadoras.

Tabela 3 - Doadores da Campanha do Senador Otto Alencar PSD/BA

\begin{tabular}{lcc}
\hline Atividade & Valor R\$ & \% \\
\hline Agribusiness & $202.198,04$ & 3,20 \\
Atividades farmacológicas & $200.000,00$ & 3,17 \\
Bebidas & $1.376 .276,47$ & 21,80 \\
Construção civil & $3.271 .220,79$ & 51,81 \\
Hidrelétrica & $132.789,39$ & 2,10 \\
Outros & $435.317,34$ & 6,89 \\
Petrolífera & $200.000,00$ & 3,17 \\
Siderúrgica & $51.758,00$ & 0,82 \\
Sistema Financeiro & $344.188,21$ & 5,45 \\
Têxtil & $100.000,00$ & 1,58 \\
\hline Total & $6.313 .748,24$ & 100,00 \\
\hline
\end{tabular}

Fonte: Adaptada de Brasil (2014). 
Conforme destaca a Tabela 3, do total arrecadado de $\mathrm{R} \$$ 6.313.748,24 para a realização da campanha eleitoral pelo senador Otto Alencar, mais de 50\% foi doado por empresas vinculadas à atividade de construção civil, enquanto empresas vinculadas às atividades de bebidas doaram cerca de $20 \%$.

No biênio 2017/2018, o presidente da CMA é o Senador Davi Alcolumbre do DEM/AP. Desse modo, a Tabela 4 apresenta os doadores a campanha eleitoral do Senador, os quais são apresentados por atividades principais exercidas pelas empresas doadoras.

Tabela 4 - Doadores da Campanha do Senador Davi Alcolumbre DEM/AP

\begin{tabular}{lcc}
\hline Atividade & Valor R\$ & \% \\
\hline Construção civil & $100.049,80$ & 4,91 \\
Frigorífico & $138.005,45$ & 6,78 \\
Outros & $940.877,00$ & 46,20 \\
Papel e celulose & $100.000,00$ & 4,91 \\
Sistema Financeiro & $757.686,51$ & 37,20 \\
\hline Total & $2.036 .618,76$ & 100,00 \\
\hline
\end{tabular}

Fonte: Adaptada de Brasil (2014).

Conforme apresentado na Tabela 4, do total arrecadado de $\mathrm{R} \$$ 2.036.618,76 para a realização da campanha eleitoral pelo Senador Davi Alcolumbre do DEM/AP, aproximadamente 37\% teve como origem empresas vinculadas à atividade do sistema financeiro; já as empresas vinculadas às atividades de frigorífico doaram $7 \%$ aproximadamente.

Portanto, observa-se que as empresas das seguintes atividades são as principais financiadoras das campanhas eleitorais dos Senadores a presidirem a Comissão de Meio Ambiente, Defesa do Consumidor e Fiscalização e Controle, do Senado Federal, no período de 2015 a 2018: construção civil, sistema financeiro e frigoríficos.

\section{Considerações finais}

Este estudo objetivou demonstrar o que é um lobby, a atuação dele nos financiamentos de campanhas eleitorais, a influência do lobby e das empresas sobre políticas relacionadas ao meio ambiente nas Comissões das casas legislativas, que são a Câmara dos Deputados e o Senado Federal no Brasil.

Ao final da pesquisa, constatamos que os setores que mais financiaram as campanhas foram a construção civil e o sistema financeiro. Consideramos que estes sejam os setores que mais investiram devido aos grandes eventos que aconteceram no país como as Olimpíadas no Estado do Rio de 
Janeiro e a Copa do Mundo, que precisaram de grande financiamento e infraestrutura para que pudessem ser realizados.

É possível deduzir que, em muitas situações, os parlamentares representam os interesses daqueles que, pela via econômica, viabilizaram a campanha eleitoral para que estes pudessem ocupar o cargo de legisladores. Para tanto, em muitas situações, os legisladores atendem prioritariamente aos interesses de grupos econômicos que os auxiliaram com doações as campanhas eleitorais. Logo, os grupos econômicos, por meio do financiamento das campanhas eleitorais, trocas de favores e outros atos espúrios, têm interferência e influência direta no processo legislativo. E, em muitas situações, o interesse público é ignorado, embora este seja uma das principais premissas à representatividade da população no Congresso Nacional.

Visando ao financiamento da próxima eleição, o político acaba sendo influenciado a seguir orientações que podem não servir ao clamor da população; porém, na visão dele ou do próprio partido, são necessárias para a garantia de sua reeleição, mesmo que a notícia se mostre negativa para os seus eleitores.

Uma solução possível para o caso seria a aprovação de lei que regulamentasse o lobby e a sua prática, tornando o processo o mais transparente possível.

\section{Referências}

ACCIOLY, Inny; SÁNCHEZ, Celso. Antiecologismo no Congresso Nacional: o meio ambiente representado na Câmara dos Deputados e Senado Federal. Desenvolvimento e Meio Ambiente, n. 25, p. 97-108, jan./jun. 2012.

BARDIN, Lawrence. Análise de Conteúdo. Tradução de Luís Antero Reto e Augusto Pinheiro. São Paulo: Setenta, 2011.

BORGES, Tiago Daher Padovezi. O financiamento empresarial e as campanhas legislativas de 2014: uma análise exploratória das doações diretas aos candidatos a Deputado Federal. Política e Sociedade, v. 15, n. 32, p. 102-125, jan./abr. 2016.

BRASIL.Constituição da Republica Federativa do Brasil, de 5 de outubro de 1988. Disponível em: <http://www.planalto.gov.br/ccivil_03/constituição/ constituição.htm>. Acesso em: 12 ago. 2016.

BRASIL. Tribunal Superior Eleitoral. Prestação de Contas Eleitorais 2014. 2014. Disponível em <http://inter01.tse.jus.br/spceweb.consulta.receitasdespesas2014/ resumoReceitasByCandidato.action>. Acesso em: 12 ago. 2016.

. Câmara dos Deputados. Histórico e atribuições. 2016a. Disponível em <http://www2.camara.leg.br/atividade-legislativa/comissoes/comissoespermanentes/cmads/conheca-a-comissao/index.html>. Acesso em: 12 ago. 2016. 
Senado Federal. Comissão de Meio Ambiente, Defesa do Consumidor

e Fiscalização e Controle. 2016b. Disponível em <http://legis.senado.leg.br/ comissoes/comissao?3\&codcol=50>. Acesso em: 12 ago. 2016.

Lei Federal no 13.165 de 2015. Disponível em <http://www.planalto.gov. br/ccivil_03/_Ato2015-2018/2015/Lei/L13165.htm>. Acesso em 02 set. 2018.

DINIZ, Eli; BOSCHI, Renato. O Legislativo como arena de interesses organizados: a atuação dos lobbies empresariais. Locus: Revista de História, Juiz de Fora, v. 5, n. 1, p. 7-32, 1999.

ORGANIZAÇÃO DAS NAÇÕES UNIDAS (ONU). Meio Ambiente. [s. d.]. Disponível em <https://nacoesunidas.org/acao/meio-ambiente/>. Acesso em: 14 ago. 2016.

SZTUTMAN, André Medeiros; ALDRIGHI, Dante Mendes. Financiamento das campanhas eleitorais de 2006 por grupos econômicos e empréstimos do BNDES. In: ENCONTRO NACIONAL DE ECONOMIA, Disponível em: <https://www.anpec.org.br/encontro/2012/inscricao/files_I/i4-7c3a93e1a21d7bd 164add14eeae29266.pdf >. Acesso em 02 set. 2018. ANPEC, 2012.

VERGARA, Sylvia C. Métodos de Pesquisa em Administração. 3 ed. São Paulo: Atlas, 2008.

Métodos de Pesquisa em Administração. 4. ed. São Paulo: Atlas, 2010.

Submetido em: 19/02/2018

Aceito em: 03/08/2018 


\title{
POLITICS AND THE ENVIRONMENTAL: THE INFLUENCE OF LOBBYING ON LEGISLATIVE DECISIONS
}

\begin{abstract}
This paper intends to analyze the influence of lobbying on the Brazilian legislative power, specifically the pressure exerted on the presidents of the Committee on the Environmental and Sustainable Development, the Chamber of Deputies and the Committee on Environment, Consumer Protection and Inspection and Control, of the Federal Senate. At first it is necessary to characterize the lobby and in what way it acts, later the identification of the presidents of each commission within the legislative houses is carried out and then the collection of data of campaign financing of each one of them. We observed that in the electoral campaigns of the studied parliamentarians, companies like agribusiness, civil construction, financial system, among others acted financiers. The companies in these segments have a direct influence on the positioning and decisions made by legislative houses, since the economic factor is a differential in the Brazilian electoral campaigns.
\end{abstract}

Keywords: Environment. Election campaign. Lobby. 